\title{
Analysis of Bone-Implant Interface with Osseoinduction Treatment
}

\author{
Julia Mirza Rosca, Pedro Socorro Perdomo, Nestor Florido Suarez and Maximina Monzon mayor \\ University of Las Palmas de Gran Canaria, Las Palmas de GC, Canarias, Spain
}

The interactions of tissues, bones and body fluids with biomaterials are an area of crucial importance to all kinds of medical technologies. The implants need to integrate with surrounding tissues to restore adequate function, without releasing harmful chemical products or significantly modifying the local environment.

Even since the 1980s the titanium alloys are intensively applied in the manufacturing of orthopedic devices, it was reported [1] that $\mathrm{V}$ is toxic in vitro at concentrations below those of synovial fluids in vivo. The administration of metallic powders to L929 and osteoblast MC3T3-E1 cells showed that Nb had no effect on their relative growth ratios [2] and for this reason it was developed an alternative alloy, Ti6Al7Nb, in which the vanadium was exchanged with niobium. Today Ti6Al7 Nb alloy is the preferred choice for cementless total joint replacement.

In this study a chemical treatment was attempted to prepare an osseoinductive surface: immersion in $\mathrm{NaOH}$ aqueous solution then dried at $40^{\circ} \mathrm{C}$ and heated up to $600^{\circ} \mathrm{C}$ for 1 hour and cooled to room temperature [3]. After osseoinductive treatment, the material was implanted in animal's tibiae (mini-pig). At 6 months after implantation, the animals were sacrificed and the segments of the proximal tibia epiphyses were cut off, fixed in phosphate-buffered formalin and dehydrated; finally, they were embedded in polyester resin and then cutted transversally (metal and bone together) and grounded to a thickness of 75-100 $\mu \mathrm{m}$. With these samples a lot of observations of interface bone-implant were made: TEM and SEM observations, histological examinations and SEM-EDX analysis.

It can be concluded that there aren't toxic and carcinogenic responses of animals to implant materials. The EDX detected the following metals: $\mathrm{Ti}, \mathrm{Ca}, \mathrm{P}$ and $\mathrm{Al}$; the calcium and phosphorus presented a $\mathrm{Ca} / \mathrm{P}$ ratio of 1.65 indicating that it is similar to bone mineral phase. The bone was in intimate contact with the bioactive Ti6Al7Nb implant (see Fig.1). Over time, the amount of bone directly bonding to the implant increased (see Fig.2) and the immature bone had formed in the earlier stages, matured and converted to lamellar bone. All the results revealed that the osseoinductive surface of the implant is in direct contact with newly formed bone without any intervention of a soft tissue layer. We regard osseoinductive ability of nanostructured Ti6Al7 Nb as one of the advantages of this implant in consideration for clinical applications. 


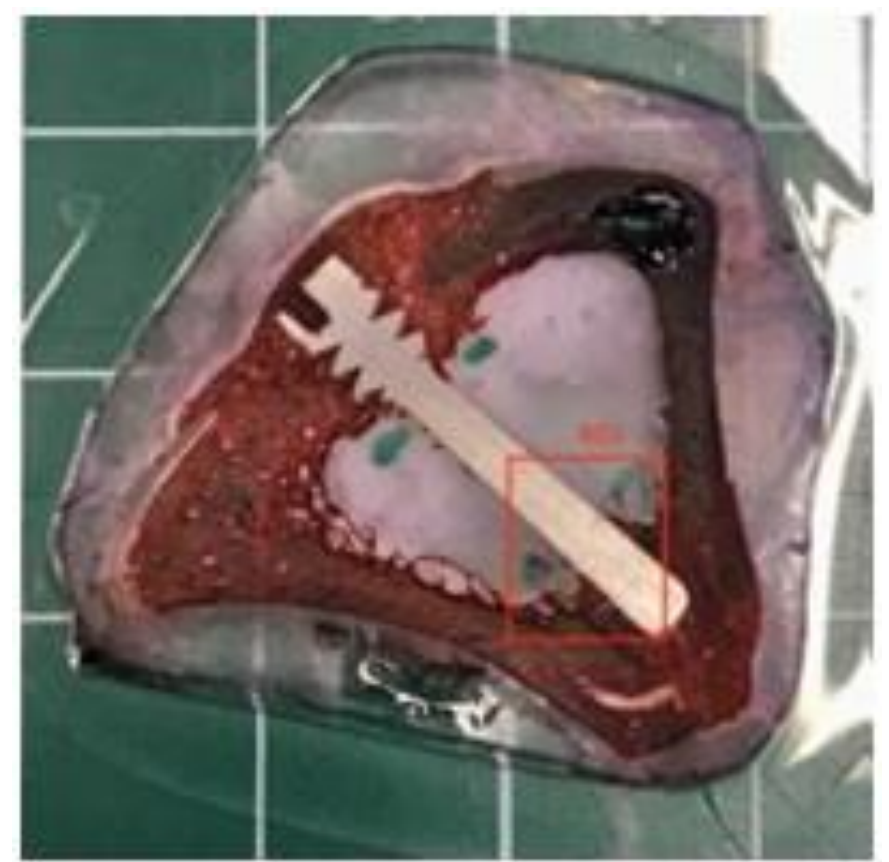

Figure 1. General view

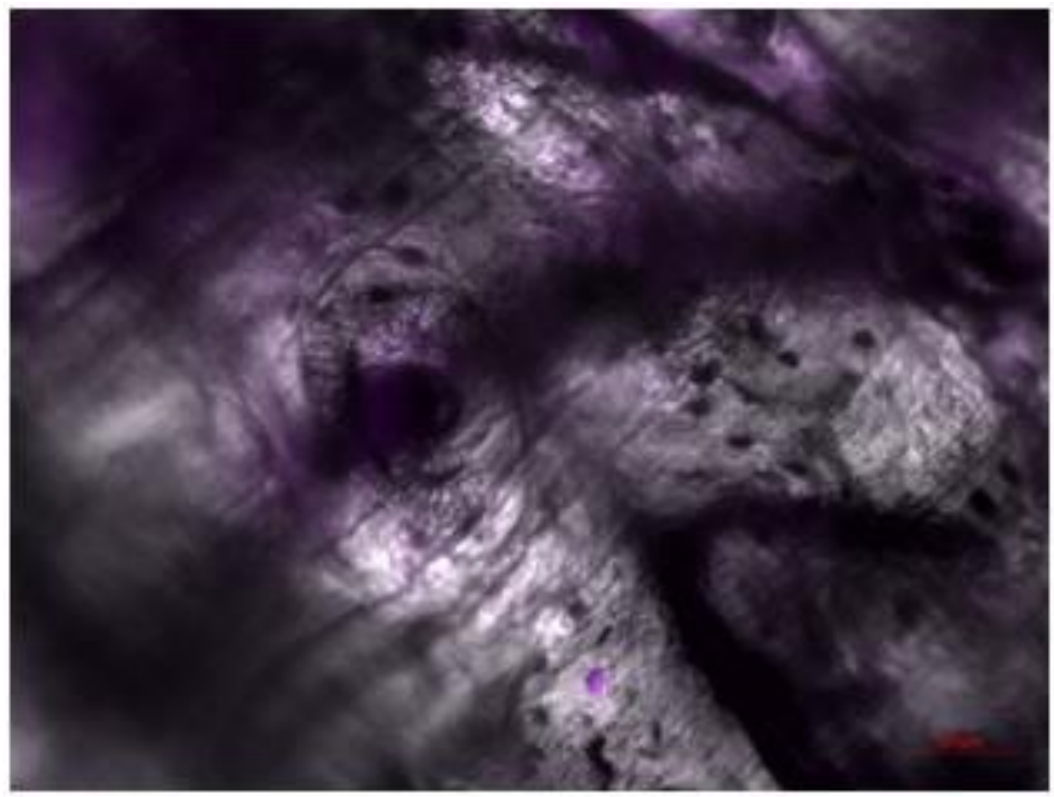

Figure 2. New bone in direct contact with the implant

\section{References}

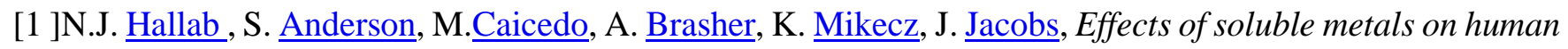
peri-implant cells, J Biomed Mater Res A. 2005;74(1):124-40.

[2] Y. Okazaki, S. Rao, Y.Ito, T. Tateishi, Corrosion resistance, mechanical properties, corrosion fatigue strength and cytocompatibility of new Ti alloys without Al and V, Biomaterials 1998, 19:1197-1215.

[3] M.Takemoto, S.Fujibayashi, M.Neo, J.Suzuki, T.Kokubo, T.Nakamura, Mechanical properties and osteoconductivity of porous bioactive titanium, Biomaterials 2005, 26(30), 6014-6023. 